\title{
Amygdala and Taste Learning
}

\author{
Andrés Molero Chamizo
}

Additional information is available at the end of the chapter

http://dx.doi.org/10.5772/47761

\section{Introduction}

The amygdala is a particular forebrain structure which is widely involved in many cognitive processes, such as attention and emotional learning, among others. The amygdala is part of the limbic system, which is critical for survival. In rats, it is located bilaterally in the medial temporal lobes, and its nuclei are similar to those of primates [1, 2]. In mammals, the amygdala is involved in the expression of many behaviours, such as fear responses, reproduction, aggressiveness and social behaviour and also in physiological processes such as modulation of the neuroendocrine and autonomic systems and homeostasis [3]. The amygdala consists of several nuclei that form a complex network of information processing. The three main nuclei of this structure are the medial, the central and the basolateral nucleus. These nuclei have complex connections with other structures; therefore it is thought that the activity of the amygdala is relevant in the modulation of some types of learning and memory [4]. In particular, the amygdala appears to participate in several complex processes underlying taste learning [5-11].

This chapter will summarize the most relevant data from animal models involving the amygdala in three complex processes underlying associative learning using a taste stimulus. The first section will aim to describe the role of the amygdala in the acquisition of the conditioned taste aversion (CTA) learning, a particular conditioning in which the subject learns to associate a novel taste stimulus with a successive visceral discomfort. The second section will review the data evidencing the role of the amygdala in the latent inhibition process of CTA that is obtained when the taste stimulus is presented to the subject several times prior to conditioning. Finally, we will discuss recent research that suggests that the participation of some cortical and subcortical structures (including the amygdala) in the influence of several contextual stimuli (such as the spatial context or time of day in the sleep/wake cycle) on the acquisition of CTA and latent inhibition of CTA. With this we hope to highlight some of the possible mechanisms of taste learning in which the different amygdaloid nuclei seem to have a specific function. 


\section{Amygdala and conditioned taste aversion learning}

This section will review the studies that implicate the amygdala in taste learning processes [12]. First, a brief description of the phenomenon of CTA will be provided. Then we will analyse the research that points to the amygdala and its nuclei as part of the brain mechanisms of CTA.

\subsection{Description of the conditioned taste aversion paradigm}

Conditioned taste aversion learning is a particular conditioning paradigm which exists for the subject to associate the consumption of a new taste with a visceral disease that occurs after. Since a delay usually separates the presentation of the taste from the visceral disease, it is suggested that the learning results from the association between the memory trace of that taste and the disease [13]. The CTA learning is vital for numerous species because the learned aversion could reduce the probability of re-experiencing the toxic effects of a harmful substance. Even though this is a conditioning process, it has some special features when compared to most other forms of associative learning. Taste aversion learning is a paradigm widely used in animal research exploring the brain mechanisms of learning and memory [14]. Therefore, we will describe the taste aversion learning paradigm, which was mainly shown in animals. In humans, CTA has also been studied to a much lesser extent than in animals. For example, taste aversion learning has been examined in humans in order to understand the neurobiology of eating behaviour. Studies using positron emission tomography (PET) have shown that the amygdala and orbitofrontal cortex are activated when processing an aversive taste stimuli $[15,16]$. Recent research with functional magnetic resonance imaging (fMRI) in humans has confirmed the involvement of the orbitofrontal cortex, anterior cingulated cortex, insular cortex and amygdala in processing highly aversive flavours [17]. Since the amygdala also seems to be involved in conditioned taste aversion in humans, it is possible that the acquisition of this learning requires biological mechanisms that are common in different species of vertebrates [18]. Moreover, because the food aversion associated with chemotherapy treatment is similar to the experimentally induced taste aversion [19], the CTA paradigm has helped to develop different strategies for dealing with the taste aversion that occurs in patients being treated with chemotherapy [20].

A crucial role in food selection processes is the ability to learn taste aversions [21]. This is particularly relevant for omnivorous species. The discrimination process between edible and harmful, or even potentially deadly, substances starts from the gustatory sensory information. This information stimulates a biological mechanism of precaution against new flavours, which facilitates the evaluation of the consequences of the ingestion of novel substances [22] and subsequently promotes the acquisition of conditioned taste aversions or preferences [8]. The initial response of caution is accompanied by a lower consumption of the novel substances. This phenomenon is called neophobia. If the sensory characteristics of the novel substance are associated with negative visceral consequences (such as poisoning), the animal will then acquire an aversion to that particular taste [23]. If the intake is 
associated with a positive visceral consequence (as in the case of an energetic food), or nonaversive, the new flavour will be recognized as being safe. Evolution has resulted in the development of neural mechanisms of attention, motivation, learning and memory that allow such identification of edible substances to be made.

Conditioned taste aversion paradigm exhibits three important features of associative learning; each feature exists separately in other classical conditioning paradigms. First, CTA can be acquired with a single pairing between the taste and the visceral discomfort $[6,13,22-$ 25]. Second, conditioned taste aversion is an example of a biological predisposition to associate certain stimuli more easily. For example, the taste-illness association occurs more easily than sound-disease or odour-disease associations [26]. The third characteristic of CTA learning refers to the delay that separates the presentation of the taste and visceral stimuli, or absence of temporal contiguity. The association between a new taste (the conditioned stimulus -CS-) and visceral consequences following its ingestion (the unconditioned stimulus -US-) results in a subsequent aversion to that taste, even though a delay of minutes or even hours (far superior to that seen in any other type of associative learning) is used. This unusual property of CTA to resist to a long inter-stimulus delay is related to the physiological processes of digestion. Indeed, in physiological conditioning, a delay always separates the ingestion from a potential poisoning. This delay is necessary for the completion of gastric digestion which results in the transport of nutrients through the gastrointestinal system and the gradual absorption of the products of digestion. Consequently, the association between gustatory and visceral stimuli must comply with this temporal requirement [27].

The experimental procedure used to induce conditioned taste aversion is a tool that has been used for decades in research into learning and the biological substrates of learning and memory [6, 11, 13, 14, 24, and 28]. In the laboratory, the procedure involves water deprivation with limited access to a daily amount of water, or water limited to a restricted time period within the day (usually 15 minutes). Once the daily amount of water consumed is stabilized, the animals receive the presentation of a new taste (representing the conditioned stimulus, generally a saccharin solution dissolved in water at $1 \%$ ) during the conditioning session. The consumption of this taste is followed twenty or thirty minutes later by a gastrointestinal distress (representing the unconditioned stimulus, generally induced by an intraperitoneal injection of lithium chloride $(\mathrm{LiCl})$, although some other aversive agents [29-36] have been used to induce aversion). Forty eight hours after conditioning, CTA tests can be used to detect the strength of the aversion to the CS previously paired with the malaise [37]. The reduction in the consumption of the CS after learning indicates more than a conditioned avoidance response. In fact, the learned aversion to taste really involves a change in the incentive properties of that stimulus, with its hedonic value becoming repulsive [38]. This learning is easily reproduced in the laboratory, and has proven to be a relevant paradigm for discovering important aspects of the neurobiological substrate involved in associative learning and memory. The following section will describe the findings that appear implicate the amygdala in the acquisition of this kind of learning. 


\subsection{Amygdaloid nuclei and acquisition of CTA}

Conditioned taste aversion learning depends on a complex neural circuit that includes brainstem areas, as well as subcortical and cortical mechanisms [8, 11, 39, and 40]. Lesion studies have provided important information about the different structures and regions of the brain involved in the acquisition of taste aversion [10, 18, 41, 42-44]. The processing of sensory information necessary for the acquisition of a taste aversion involves multiple systems. The taste system detects information from the lingual papillae and palate via the cranial facial nerve (VII), glossopharyngeal (IX) and vagus (X) [8]. The visceral sensory system receives information via the vagus nerve and area postrema of the brainstem [45]. The information from both sensory systems are transported separately to the primary relay brainstem nuclei (nucleus of the solitary tract) and secondary relay (parabrachial nucleus), as well as to brain structures involved in processing visceral and taste, such as the thalamus, the insular cortex and the amygdala [46]. The processing of taste qualities [47] and subsequent association with the visceral effects of toxicity [48-50] requires complex neuroanatomical relationships in which the amygdala seems to be involved [51].

The amygdala and other cortical and subcortical areas are related to the brainstem associative processes necessary for taste aversion conditioning [41, 52-57]. In reference [52], the blockade of protein synthesis or beta-adrenergic receptors in the central amygdala blocks acquisition but not extinction of CTA. The same procedure in the basolateral amygdala blocks extinction but not acquisition of this learning. The authors of this research argue that the neural circuit that makes the acquisition of taste aversion memory possible and the extinction of the aversion requires the activity of the amygdala. However, the involvement of the amygdala and other structures in the associative processes of CTA has been studied by examining protein synthesis associated with learning. In one research it has been observed that the long-term aversive taste memory requires protein degradation in the insular cortex and the amygdala [56]. The selective involvement of the amygdala in CTA has also been analysed in other ways in animal models. There are studies of receptor expression during taste aversion learning [58,59], studies of the c-Fos expression [60] and other genes [61] in the amygdala, studies of receptors blockade of the amygdala [62] and numerous studies using brain lesions [63], all in the CTA paradigm. For example, possible changes of the leptin receptor expression in the basolateral amygdala in relation to CTA acquisition have been analyzed [59]. Leptin receptor mRNA in the brain was analyzed by in situ hybridization and the expression of this receptor was assessed by immunohistochemistry method. Both measures were significantly higher after the formation of CTA. The authors concluded that the amygdaloid leptin receptor is involved in neuronal communication for CTA formation. Other studies [62] have also implicated other amygdaloid receptors in CTA, particularly the noradrenergic receptors. The researchers administered selective bilateral microinfusions of the beta-adrenergic antagonist propranolol into the basolateral amygdala immediately before intraperitoneal $\mathrm{LiCl}$ injections. This procedure disrupted CTA memory and the authors proposed that the basolateral amygdala is a critical structure in modulating the consolidation of taste memory. Genetic studies have confirmed the relation between amygdala and CTA. In this regard, studies have recently identified some specific genes in 
the amygdala (associated with neuropeptides, G protein-coupled receptors, ion channels, kinases and phosphatases) that contribute to CTA acquisition [61].

Regarding the lesion procedure; the studies that describe a lesion in the amygdala have not been decisive so far as they have shown a weak effect on taste learning or even no effect at all. However, electrolytic lesions of amygdala were shown to attenuate or disrupting CTA $[64,65]$ and also been shown to affect the neophobia phenomenon [65, 66]. Taken together with other studies that reported a selective involvement of the basolateral nucleus in CTA [67], it has been suggested that the effect of the basolateral injury on CTA is due to an alteration of the proper appreciation of the gustatory signal novelty, which could have affected the subsequent expression of taste aversion $[63,68]$. Subsequent studies have confirmed this hypothesis by reporting a selective effect on CTA [69] or a dual effect on neophobia and taste aversion [70] after basolateral nucleus lesion.

Moreover, electrolytic lesioning of the basolateral nucleus of the amygdala did not induce any effect on the formation of taste aversion in different studies [71-73]. Some authors have argued that the involvement of the basolateral amygdala in CTA is indirectly mediated by its interactions with the nucleus of the solitary tract [74] or the insular cortex [71, 72] therefore showing that the electrolytic lesions indirectly affects the acquisition of taste aversion. Nevertheless, other brain manipulation tools and neurophysiological techniques have also implicated the basolateral nucleus of the amygdala in the acquisition of CTA learning [51, 75-80]. In other studies [51] it has been found that specific neurons in basolateral amygdala respond to convergent taste stimulus and unconditioned stimulus information during CTA. The authors used a procedure of analysis of temporal gene transcription by fluorescence in situ hybridization in order to locate these populations of neurons. In [77], it was shown that CTA memory needs protein synthesis in the basolateral amygdala, and in [79] it has been proposed that the basolateral amygdala interacts with the insular cortex to modulate the memory consolidation because the infusions of the betaadrenergic antagonist propranolol administered into this nucleus blocked the enhancing effects on CTA of a muscarinic agonist infused into the insular cortex.

The local injection of excitotoxic agents (such as NMDA or ibotenic acid) induces a more selective lesion in the cell bodies of the target structure. Although the excitotoxic lesioning of the amygdala has not always resulted in deterioration of CTA [71, 81, 82], the excitotoxic lesions of the basolateral amygdala often reproduce the effects obtained with electrolytic lesion on CTA [10, 44, 50, 83-86]. In contrast, the excitotoxic lesion of the central amygdala does not affect the formation of taste aversion [44, 83, 84, and 87]. The possible role of the central nucleus of the amygdala in CTA seems to be related to the processing of visceral information. For example, immunohistochemistry has found increased levels of a specific protein kinase associated with the memory of CTA in the cells of the central nucleus of the amygdala after injection of a high dose of LiCl-induced visceral malaise (US) [88]. A local microinjection of an inhibitor of this kinase into this nucleus decreased the strength of the CTA as well as the levels of this protein in the central amygdala. The authors of this study proposed that the intracellular levels of this protein kinase in the central amygdala are critical to process the visceral information in CTA. Therefore, it seems that the amygdaloid 
nucleus, which is involved in the acquisition of CTA, is the basolateral nucleus. In this regard, an unpublished study conducted in our laboratory has shown that excitotoxic lesions of the basolateral amygdala decreases taste aversion but does not disrupt the learning. In this study we performed bilateral excitotoxic lesions in the basolateral nucleus of the amygdala by local injection of NMDA and compared these animals' learning with two control groups. One was sham-lesioned in the amygdala and one with a lesion in the hippocampus, a structure not involved in CTA. The results showed a learning impairment in the case of animals with a basolateral lesion, compared with both control sham- and hippocampus-lesioned groups (see Figure 1).

\section{-AVERSION (\%)}

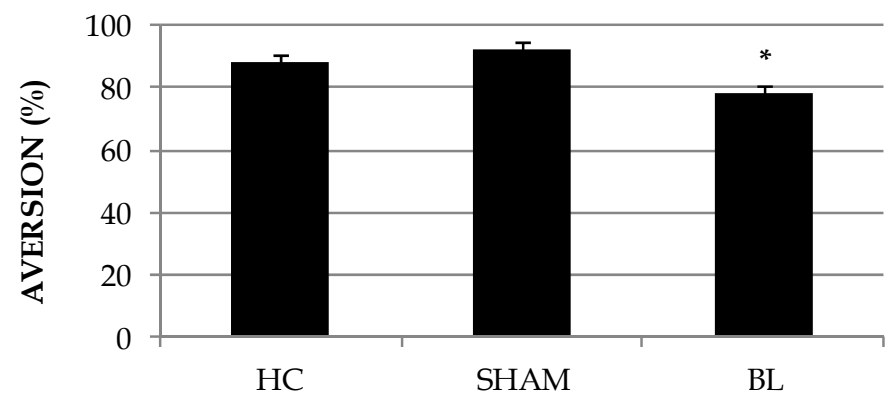

Figure 1. Percentage of taste aversion to saccharin in animals with lesion in the hippocampus (HC) or the basolateral amygdala (BL), as well as in the sham group. The percentage was calculated as a ratio between the saccharin consumed the day of acquisition of learning / saccharin consumed the day of acquisition of learning + saccharin consumed the testing day [X100].

Figures 2 and 3 show stained brain sections of a sham-lesioned animal and an animal with excitotoxic lesion in the basolateral amygdala induced by local injection of NMDA.

These results suggest that the basolateral amygdala is part of the brain circuitry of CTA, but is not a necessary structure for this learning. In other studies, the inactivation of the basolateral amygdala has not disrupted the CTA [89], or has impaired the learning but did not prevent its acquisition [7]. Therefore, our study, which used excitotoxic lesions, is consistent with the hypothesis that the formation of taste aversion does not require the integrity of the amygdala, although it does seem to be an important structure in the modulation of CTA [41] since the selective lesion of the basolateral amygdala reduces, but does not prevent, the learning. The reversible lesion studies also suggest that the amygdala, or any of its nuclei, is involved in the neural mechanism responsible for CTA learning. For example, the inactivation of the amygdala using local microinfusions of tetrodotoxin (TTX) has confirmed the involvement of this structure in the acquisition and recovery of CTA [7, 90].

In summary, the evidence indicates that the amygdala is part of the neurobiology of taste aversion learning [51, 63, and 91]. Although the exact mechanism is unknown, the data 
suggest that anatomical and functional relationships between amygdala and insular cortex are necessary for the correct acquisition of conditioned aversion [79, 92]. Research also indicates that the projections from the amygdala to the hypothalamus $[93,94]$ and, in particular, to the brainstem nuclei involved in taste aversion learning [46,74,95-99] also play a significant role in this kind of conditioning.
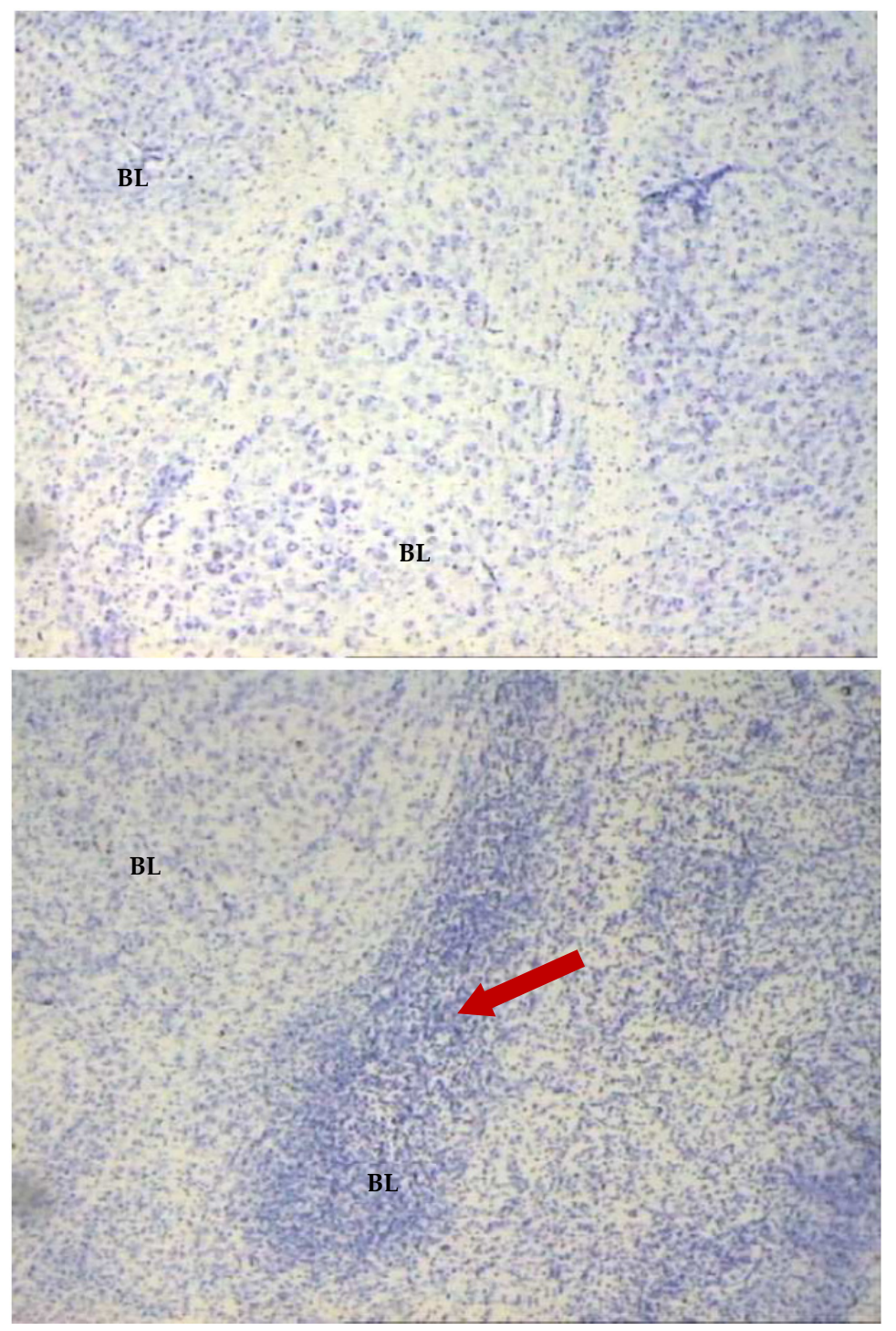

Figure 2. Section of the brain of a sham animal (above) and an animal with excitotoxic lesion in the basolateral (BL) amygdala (below). The arrow indicates the reaction of the microglia in this nucleus of the amygdala induced by the neurotoxin, compared with sham animal (image amplified 40x). 

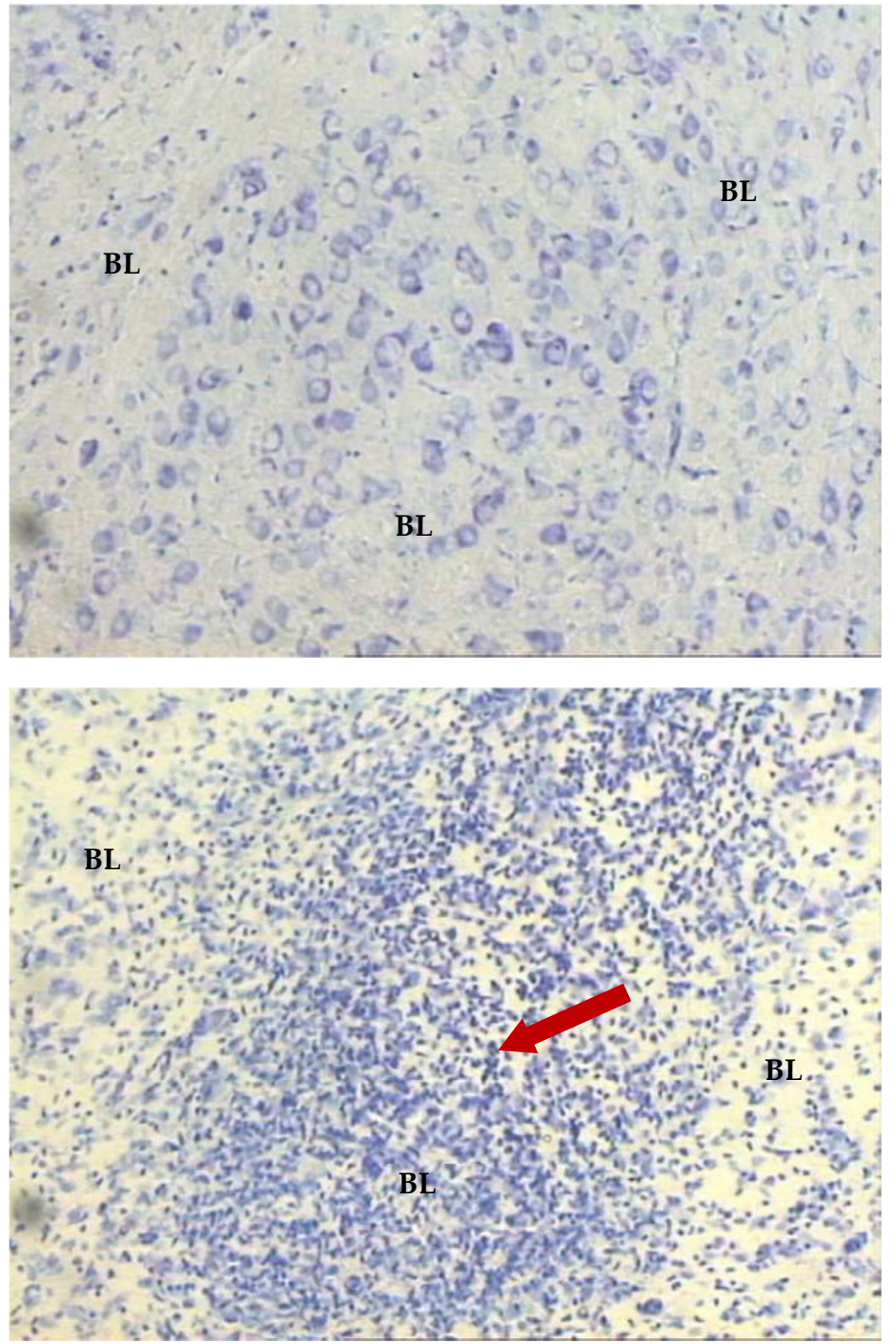

Figure 3. Detail amplified 100x of the sections of the Figure 2. 


\section{Latent inhibition and amygdala}

Latent inhibition refers to a reduction in the conditioned aversion to a stimulus that has been previously pre-exposed without reinforcement. This phenomenon is easily reproduced in the laboratory and is demonstrated by presenting a stimulus several times (for example a sweet solution), which will subsequently be paired with a visceral malaise during one acquisition session. The latent inhibition response results in an absence, or a significant decrease, in the aversive response to the conditioned stimulus during the test session. In the following sections we will describe the phenomenon of latent inhibition in the CTA paradigm, and then review the studies implicating the involvement of the amygdala in the mechanisms underlying this learning.

\subsection{Latent inhibition of taste aversion learning}

The effect of latent inhibition has been demonstrated consistently in CTA learning [100-105]. Non-reinforced pre-exposure to a particular taste reduces the magnitude of CTA when this taste is subsequently associated with gastrointestinal discomfort. The experimentally obtained latent inhibition (LI) results in a higher aversion to the taste not experienced before the acquisition, in comparison to the aversion to the taste that has been pre-exposed. This reduction in the conditioned response is comparable to that obtained by pre-exposure in conventional experiments of classical conditioning [101,104].

Several cortical areas and subcortical structures have been specifically involved in the neural mechanisms that support latent inhibition depending on the learning paradigm used. For example, latent inhibition of the CTA, the fear conditioning and the cued fear conditioning, the eye blink response and some appetitive conditioning [106-114]. Some of the structures and systems involved in latent inhibition are the hippocampus, the mesolimbic dopaminergic pathway, the entorhinal cortex and the nigrostriatal dopaminergic pathway [115]. In addition, the nuclei of the amygdala have also been studied in relation to latent inhibition in several learning paradigms, although in CTA the results do not confirm the involvement of any of these nuclei in this phenomenon [110].

\subsection{Amygdala and latent inhibition of taste aversion learning}

According to [113], a complex neural circuit involving the connection of the medial prefrontal cortex, the striatum and the amygdala with the nucleus accumbens, is involved in the phenomenon of latent inhibition. The specific role of each component of the circuit could explain the discrepancy between the results obtained with lesions. For example, [114] has reported that electrolytic lesioning of the basolateral amygdala leaves latent inhibition intact in a conditioned emotional response procedure. In contrast, in [116] it was observed that excitotoxic lesioning of the basolateral amygdala interferes with the effect of pre-exposure to a light-food pairing in a reinforcer devaluation procedure. Furthermore, in an appetitive conditioning task it was found that the lesions in the basolateral amygdala disrupted the 
latent inhibition [117]. The authors of this research concluded that the connections between the basolateral amygdala and the entorhinal cortex are crucial in the formation of latent inhibition. Molecular biology has also provided extensive information that suggests the involvement of the amygdala in latent inhibition depends on NMDA receptors. Blockade of these receptors in the basolateral amygdala by selective antagonists prevents the expression of latent inhibition in a fear conditioning task [118]. Moreover, it has been found that excitotoxic lesioning of the central amygdala does not affect the latent inhibition in a Pavlovian appetitive conditioning task [119] or a reinforcer-devaluation procedure [116]. Nevertheless, [120] observed an intense production of c-Fos protein in central amygdala neurons (which is associated with intense cellular activity), which correlated with the decrease in the conditioned response to a familiar stimulus. Therefore, although the real function of the amygdala in latent inhibition is still being researched, the data appear to suggest some involvement of the basolateral amygdala in this learning. These findings also seem to confirm that the regions involved in the brain circuit that support the latent inhibition process may be different, depending on the type of conditioning used.

Experiments on latent inhibition in CTA have not yet permitted us to define the neural mechanisms supporting the learning processes of this paradigm, although CTA is probably the paradigm that has provided the most documented information about the neurobiology of latent inhibition. The hippocampal lesion studies have attempted to demonstrate the involvement of this structure in latent inhibition but the results have not been decisive. For example, in reference to [121] it has been observed, by computer simulations, that depending on the behavioural protocol (particularly the total time of pre-exposure), the perception of novelty after hippocampal lesion could be larger, equal to, or smaller compared to the novelty in control animals. In contrast, the striatum has been clearly involved in latent inhibition of taste aversion learning [111, 122]. Regarding the amygdala; lesions of the basolateral nucleus have also not shown detrimental effects on latent inhibition of conditioned taste aversion [123]. In latent inhibition of CTA, the dopaminergic system of the basolateral amygdala has also been examined and has shown that dopamine in this nucleus does not appear to modulate the latent inhibition but rather the phenomenon of prepulse inhibition [110].

In order to test the involvement of the amygdala or the hippocampus in latent inhibition of CTA, we tested the effect of bilateral excitotoxic lesions of both structures in this paradigm. The results of this study showed that neither lesion of the amygdala (mainly located in the basolateral nucleus) nor hippocampus affected latent inhibition of CTA (see Figure 4).

Figures 5 and 6 show stained animal brain sections with excitotoxic lesion in the hippocampus or the basolateral amygdala, respectively, induced by local injection of NMDA.

Taken together, the results of this study indicate that the expression of latent inhibition in taste aversion learning paradigm does not require the participation of the hippocampus or amygdala. 


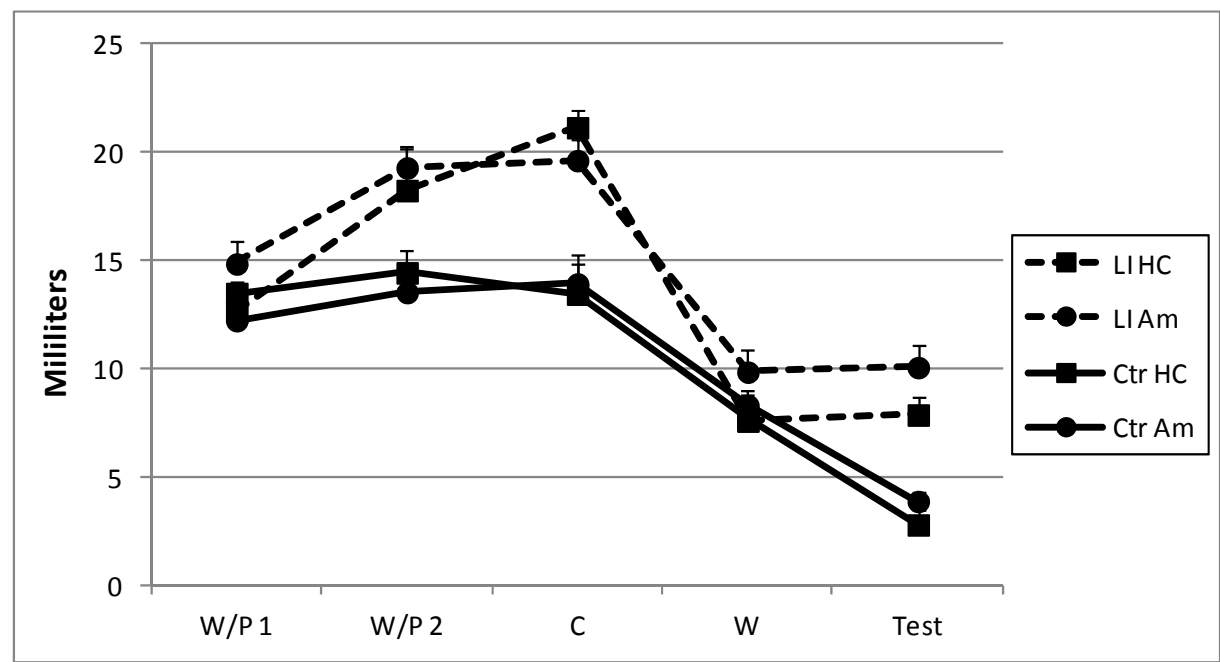

Figure 4. Representation of the average quantity of fluid in milliliters ingested by each of the groups (latent inhibition -LI- and control -Ctr-, with lesion in hippocampus -HC- or amygdala -Am-) over the days $(\mathrm{W} / \mathrm{P}=$ water vs. pre-exposure to saccharin $-\mathrm{CS}-; \mathrm{C}=$ conditioning; $\mathrm{W}=$ recovery with water; Test).

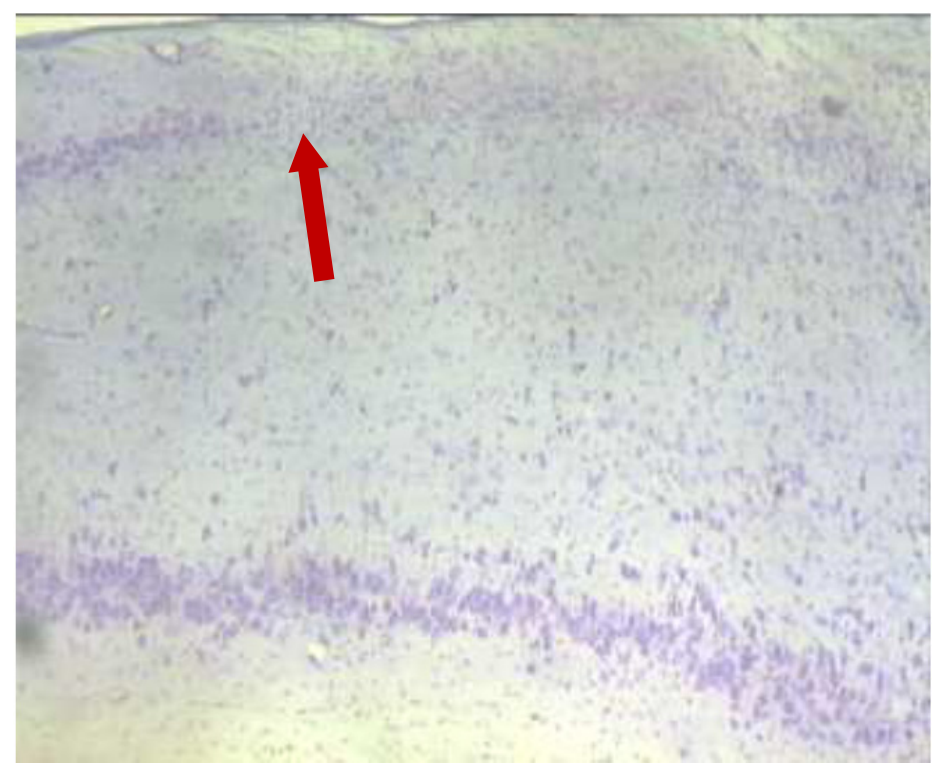

Figure 5. Section of the brain of an animal with excitotoxic lesion in the hippocampus. The arrow indicates the neurodegeneration of the CA1 hippocampal region induced by the neurotoxin (image amplified 40x). 

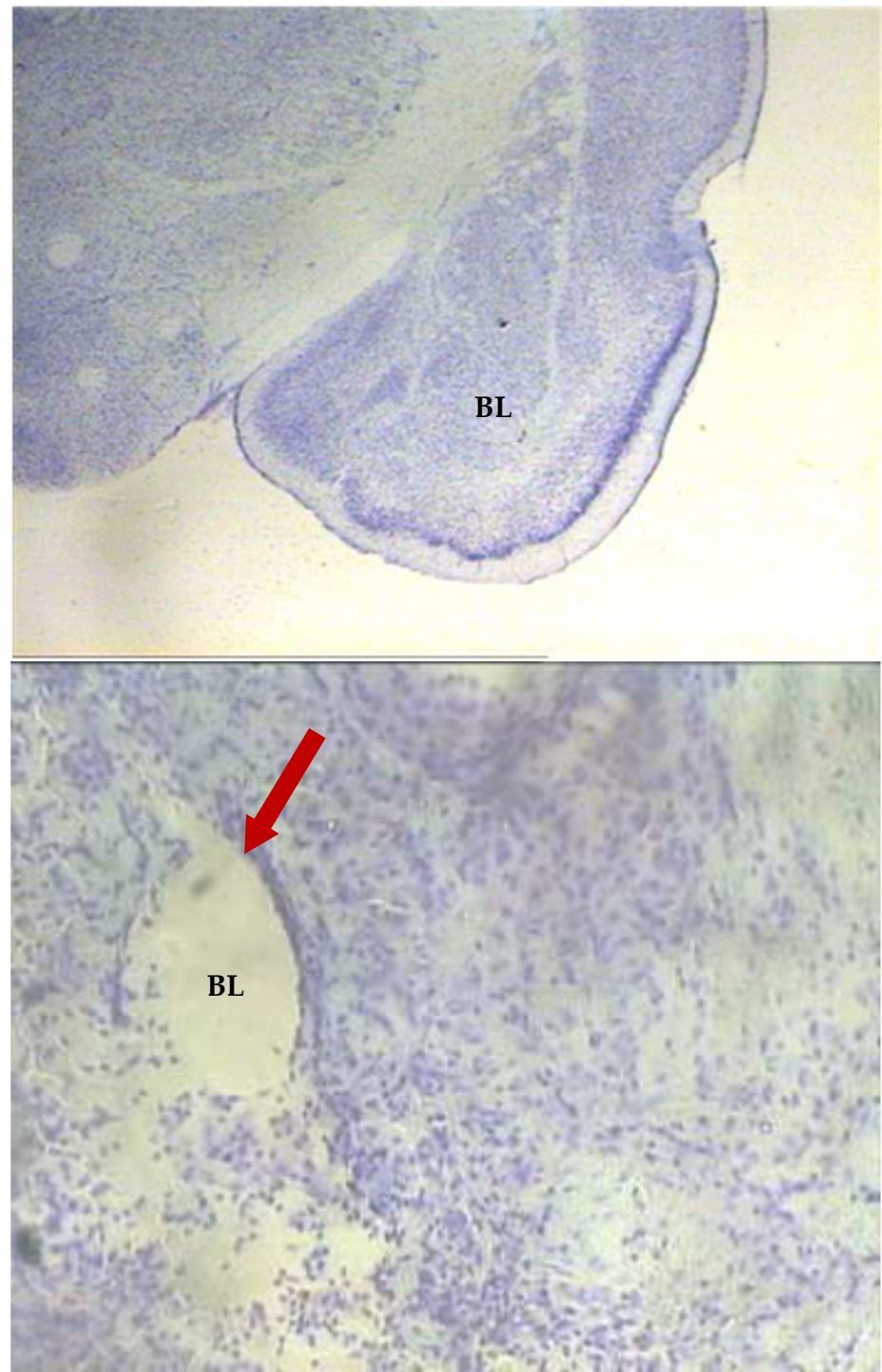

Figure 6. Section of the brain of an animal with lesion in the basolateral nucleus (BL) of the amygdala (above). Below, the arrow indicates the neuronal loss induced by NMDA in the basolateral amygdala (image amplified 40x).

\section{Context, taste learning and amygdala}

Contextual cues can modulate the conditioned response in numerous paradigms of learning. The brain mechanisms supporting this contextual effect on learning are not fully known. 
The research indicates that the hippocampus and the amygdala participate in a different way in the context-learning relation, depending on the contextual cues and the behavioural paradigm used. The following sections will review the effects of context on learning and describe the involvement of the amygdala and hippocampus in the contextual modulation process of taste learning.

\subsection{Effects of context on taste learning}

Different contextual cues, both physical and interoceptive, can influence the processes that lead to associative learning [124-126]. The most explored contextual cue is the spatial context, represented by the physical characteristics of the experimental box [124,127]. For example, latent inhibition of fear conditioning [128] and latent inhibition of CTA are sensitive to the effects of a change in spatial context [101, 129, and 130]. Similarly, taste aversion learning [131] and its extinction [132] are also sensitive to the spatial context of learning. However, the influence of temporal context in associative processes is also a good model for understanding the mechanisms of learning and memory [133]. Regarding the modulating effect of time of day, we have shown in our laboratory that the time of day in the sleep/wake cycle acts as a contextual cue and modulates latent inhibition of taste aversion learning [134] and CTA retrieval [135].

The neurobiological processes underlying contextual effects on associative learning may vary depending on the characteristics of the contextual cues involved and the learning paradigm used. In this sense, the hippocampus and the amygdala appear to be specifically involved in the contextual effects on conditioning, depending on the type of learning paradigm. The hippocampus seems to be involved in memory processes and contextual learning [136], mainly in the paradigm of fear conditioning and in spatial tasks, such as the Morris water-maze [137-139]. Some reports also suggest that the amygdala is part of the brain mechanism that allows the context to influence fear conditioning [140-142] and place conditioning [143]. The amygdala appears to be an important structure involved in the effects of context on other forms of associative learning, for example, on conditioned potentiation of eating [144]. The next section will evaluate the role of the amygdala and hippocampus in the modulating effects of context on taste learning.

\subsection{The limbic system and the effect of context on CTA}

The spatial context dependency of the latent inhibition phenomenon appears to involve the activity of the hippocampus $[120,121,145,146]$. Temporal context dependency also seems to be mediated by the hippocampus in the paradigm of latent inhibition of taste aversion learning [147], as well as in CTA [14]. However, no studies have reported the role of the amygdala in the temporal modulation of taste learning [134,135]. It is possible that the amygdala is involved in CTA selectively but not in the phenomenon of latent inhibition in this paradigm, nor in the contextual dependency of this phenomenon. This possibility can be contrasted with the apparent involvement of the hippocampus in the contextual effects on latent inhibition of CTA [147], but not in taste aversion learning. To elucidate this 
differential involvement of both structures, we have performed some experiments aimed at evaluating the effect of a change in temporal context between pre-exposure and conditioning in animals with bilateral excitotoxic lesion in the amygdala or the hippocampus. These groups were further divided into two subgroups, one consisting of animals pre-exposed to the taste (CS) and conditioned at the same time of day (groups "same") and the other one pre-exposed and conditioned at different times of day (groups "different").

Figure 7 shows the consumption of animals throughout the behaviour procedure. All groups were pre-exposed and conditioned in different temporal contexts (groups "different") consumed significantly less (except the group with hippocampal lesion) that the "same" groups in test days. Therefore, a change in the time of day between pre-exposure and conditioning disrupted the latent inhibition learning of CTA. Nevertheless, the group with lesion in the hippocampus did not show this temporal context specificity, and the consumption of these animals after conditioning was similar to that of the "same" groups.

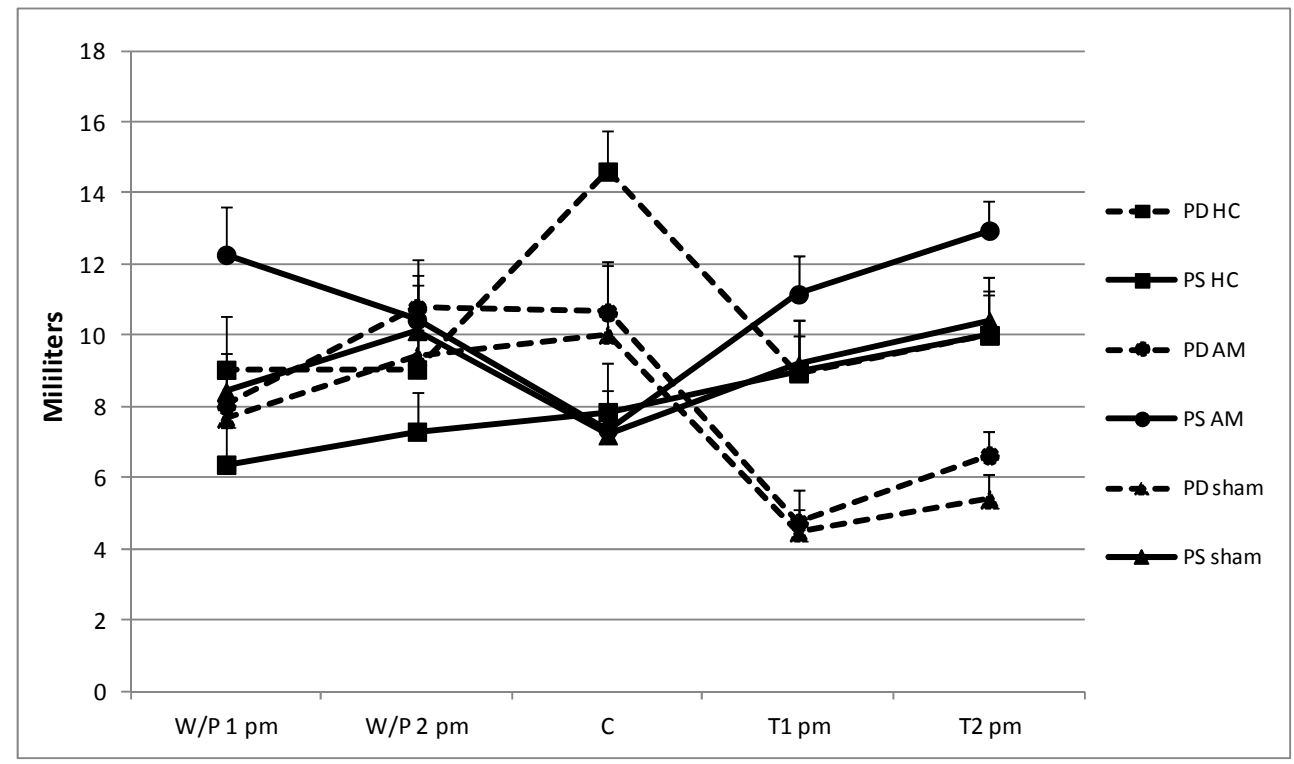

Figure 7. Representation of the average quantity of fluid in millilitres ingested by each of the groups (pre-exposed different -PD- and pre-exposed same -PS-, with lesion in hippocampus -HC- or amygdala -Am-, and pre-exposed different-PD- and pre-exposed same -PS- sham groups) over the days (W/P 1-2 $\mathrm{pm}=$ water vs. pre-exposure to saccharin in the evening session; $\mathrm{C}=$ conditioning in the morning different- or evening -same- sessions; T1-2 pm= tests 1 and 2 in the evening session).

Figures 8 and 9 show stained brain sections of animals with NMDA-induced excitotoxic lesion in the hippocampus or the basolateral amygdala, respectively, compared with sections of sham animals. 

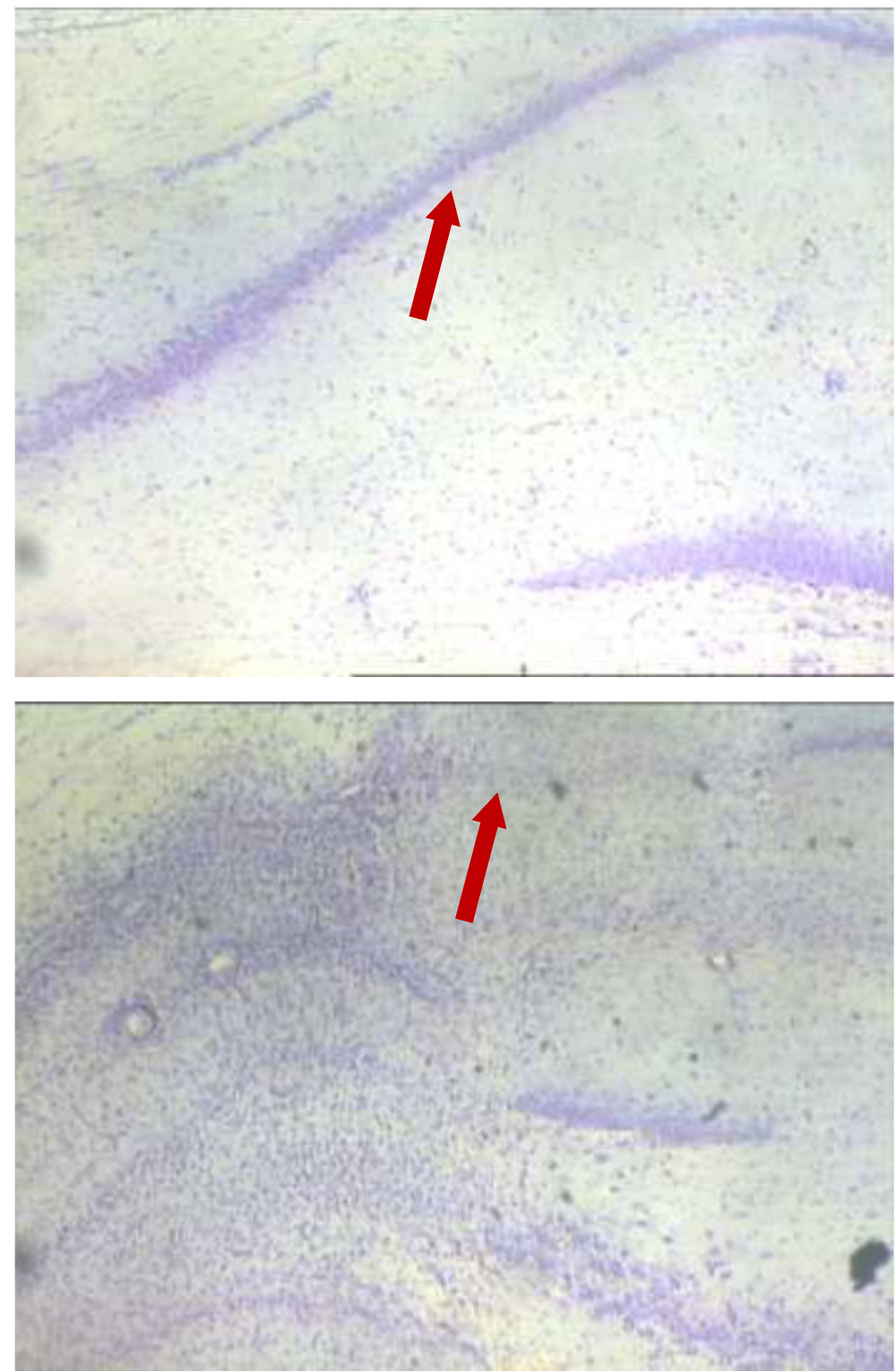

Figure 8. Section of the brain of an animal with sham lesion in the hippocampus (above). The arrow indicates intact cells of the CA1 hippocampal region. The bottom panel shows a section of the brain of an animal with hippocampal lesion. The arrow shows the destruction of the cells of the CA1 hippocampal region induced by the neurotoxin (images amplified 40x). 

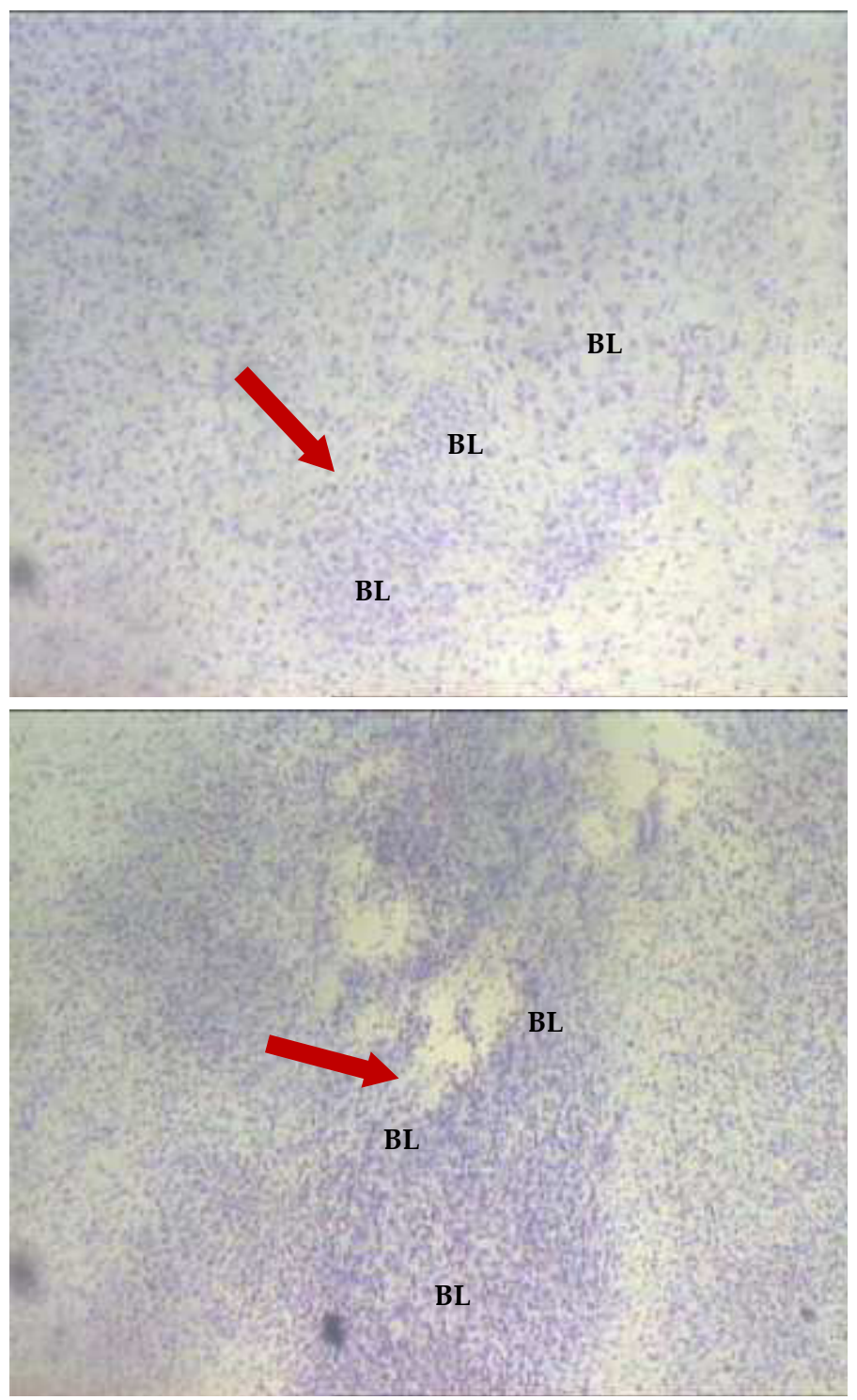

Figure 9. Section of the brain of an animal with a sham lesion in the basolateral (BL) amygdala (above). The arrow indicates intact cells of this nucleus. The bottom panel shows a section of the brain of an animal with lesion in the basolateral (BL) amygdala. The arrow shows the destruction of the cells of this amygdaloid nucleus induced by the neurotoxin (images amplified 40x).

In summary, our studies have shown that the hippocampus is necessary for the temporal specificity of latent inhibition of taste aversion learning, but not the amygdala. Subsequent studies performed in our laboratory have shown that the lesion in the hippocampus does 
not affect the phenomenon of latent inhibition in the CTA paradigm, confirming the selective function of this structure on the effects of a change of context on the phenomenon of latent inhibition of taste aversion learning. On the contrary, the amygdala is involved selectively in the acquisition of taste aversion, but not in the complex phenomena of latent inhibition and contextual modulation of taste learning.

\section{Conclusions}

The amygdala is a limbic structure involved in various processes of associative learning. Specifically, research has shown that the amygdala is part of the brain mechanism of taste aversion learning [11, 24, 41, 67, and 75]. Its role in aversive taste memory, however, is not entirely clear. Apparently, the taste memory trace requires the activity of the insular cortex [148]. The association between gustatory and visceral stimuli takes place in the brainstem $[11,41,44,60]$, although the consolidation of the memory of the association certainly seems to imply other structures such as the insular cortex or the amygdala [149]. The functional connections between the insular cortex and amygdala [92], and between the visceral processing nuclei and the amygdala [88], mean it is possible that the involvement of this structure or any of its nuclei in CTA is limited to a modulatory function, either of the sensory processing or the association between stimuli and its recovery [67]. This could explain the data obtained in some studies that shows amygdaloid lesion or its inactivation does not disrupt learning. In our study, excitotoxic lesion altered the acquisition of CTA but did not prevent learning, which may suggest that the amygdala regulates the associative process or the associative memory retrieval once established. Amygdaloid activation observed in different studies in the CTA paradigm [58, 59, and 61] is consistent with this proposal and supports the idea that the amygdala is an active structure in the acquisition of CTA but is not necessary to establish the association between stimuli or for the recovery of the association. The modulatory effects of the amygdala on learning and memory have also been described in studies of working memory and memory consolidation and extinction [150], consolidation of emotional memory [151], sensory memory representations in the cortex [152], acquisition of avoidance reactions [153], and CTA [149], among others.

The different effects on the magnitude of aversion resulting from the manipulation of the amygdala can be attributed to the particular mediation of the neophobia phenomenon in taste aversion, as well as the specific technique and procedure used. Nevertheless, in general, lesioning or inactivation of the amygdala does not prevent the CTA but reduces the magnitude of taste aversion. It seems, as described above, that the amygdala is a structure relevant for the correct acquisition of taste aversion. In this respect, our studies have shown that the excitotoxic lesioning of the amygdala does not eliminate CTA learning but decreases the acquired aversion. However, studies into the involvement of the amygdala in taste learning complex phenomena suggest that this structure is not decisive for the acquisition of latent inhibition of taste aversion learning [123], nor has its participation in the effects of spatial or temporal context on this phenomenon been demonstrated. Our experimental data support the hypothesis that the amygdala is selectively involved in the acquisition of taste 
aversion but not in the phenomenon of latent inhibition of taste aversion learning, nor in the contextual dependence of this phenomenon. In contrast, another structure of the limbic system, the hippocampus, does not seem to be involved in conditioned taste aversion nor in latent inhibition of this learning [121]. However, our experiments have shown that the contextual dependency of latent inhibition of taste aversion learning requires the integrity of the hippocampus [147], even when this structure is not necessary for the acquisition of latent inhibition in taste aversion learning paradigm. These findings demonstrate the differential functions of the amygdala and hippocampus in taste learning.

\section{Author details}

Andrés Molero Chamizo

University of Huelva, Spain

\section{Acknowledgement}

This work was supported by the University of Huelva. We are grateful to the University of Granada for the collaboration in conducting the experiments described. For helpful comments on earlier drafts of the manuscript, we also thank Jason Lauder and G. Nathzidy Rivera.

\section{References}

[1] Amaral DG., Price JL., Pitkänen A., Carmichael ST. Anatomical organization of the primate amygdaloid complex. In: Aggleton JP. (ed.) The Amygdala: Neurobiological Aspects of Emotion, Memory, and Mental Dysfunction. New York: Wiley-Liss, Inc.; 1992. p1-66.

[2] de Olmos JS. The amygdala. In: Paxinos G. (ed.) The Human Nervous System. New York: Academic Press; 1990. p583-710.

[3] Aggleton JP., editor. The amygdala: neurobiological aspects of emotion, memory and mental dysfunction. New York: Wiley-Liss, Inc.; 1992.

[4] Medina L, Bupesh M, Abellán A. Contribution of genoarchitecture to understanding forebrain evolution and development, with particular emphasis on the amygdala. Brain, Behavior and Evolution 2011; 78(3): 216-36.

[5] Bermúdez-Rattoni F. Molecular mechanisms of taste-recognition memory. Nature Reviews Neuroscience 2004; 5(3): 209-17.

[6] Gallo M, Ballesteros MA, Molero A, Morón I. Taste aversion learning as a tool for the study of hippocampal and non-hippocampal brain memory circuits regulating diet selection. Nutritional Neuroscience 1999; 2(5): 277-302.

[7] Roldán G, Bures J. Tetrodotoxin blockade of amygdala overlapping with poisoning impairs acquisition of conditioned taste aversion in rats. Behavioral Brain Research 1994; 65(2): 213-19. 
[8] Scott TR. Learning through the taste system. Frontiers in Systems Neuroscience 2011; 5(87): 1-6.

[9] Tucci S, Rada P, Hernandez L. Role of glutamate in the amygdala and lateral hypothalamus in conditioned taste aversion. Brain Research 1998; 813(1): 44-9.

[10] Yamamoto T. Neural mechanism of taste aversion learning. Neuroscience Research 1993; 16(3): 181-5.

[11] Yamamoto T, Ueji K. Brain mechanisms of flavor learning. Frontiers in Systems Neuroscience 2011; 5(76): 1-7.

[12] Yamamoto T. Neural substrates for the processing of cognitive and affective aspects of taste in the brain. Archives of Histology and Cytology 2006; 69(4): 243-55.

[13] Bures J. The CTA paradigm: terminology, methods, and conventions. In: Bures J, Bermúdez-Rattoni F, Yamamoto T. (ed.) Conditioned taste aversion: Memory of a Special Kind. New York: Oxford University Press; 1998. p14-25.

[14] Gámiz F, Gallo M. Taste learning and memory: a window on the study of brain aging. Frontiers in Systems Neuroscience 2011; 5(91): 1-6.

[15] Zald DH, Lee JT, Fluegel KW, Pardo JV. Aversive gustatory stimulation activates limbic circuits in humans. Brain 1998; 121(6): 1143-54.

[16] Zald DH, Hagen MC, Pardo JV. Neural correlates of tasting concentrated quinine and sugar solutions. Journal of Neurophysiology 2002; 87(2): 1068-75.

[17] Sarinopoulos I, Dixon GE, Short SJ, Davidson RJ, Nitschke JB. Brain mechanisms of expectation associated with insula and amygdala response to aversive taste: implications for placebo. Brain, Behavior, and Immunity 2006; 20(2): 120-32.

[18] Bernstein IL. Taste aversion learning: a contemporary perspective. Nutrition 1999; 15(3): 229-34.

[19] Walker EA. Animal models. Advances in Experimental Medicine and Biology 2010; 678: $138-46$.

[20] Jacobsen PB, Bovbjerg DH, Schwartz MD, Andrykowski MA, Futterman AD, Gilewski $\mathrm{T}$, et al. Formation of food aversions in cancer patients receiving repeated infusions of chemotherapy. Behaviour Research and Therapy 1993; 31(8): 739-48.

[21] Manabe Y, Fushiki T. Aversive sensation in the brain after eating unpalatable food. Journal of Nutritional Science and Vitaminology 2002; 48(2): 81-8.

[22] Bures J, Buresova O, Krivanek J. Brain and Behavior. Paradigms for research in neural mechanisms. Oxford: John Wiley \& Sons; 1988.

[23] García J, Kimmeldorf DJ, Koelling RA. Conditioned aversion to saccharin resulting from exposure to gamma radiation. Science 1955; 122(3160): 157-8.

[24] Bures J. Ethology, physiological psychology, and neurobiology of CTA. In: Bures J, Bermúdez-Rattoni F, Yamamoto T. (ed.) Conditioned taste aversion: Memory of a Special Kind. New York: Oxford University Press; 1998. p1-10.

[25] Scalera G. Effects of conditioned food aversions on nutritional behavior in humans. Nutritional Neuroscience 2002; 5(3): 159-88. 
[26] García J, Koelling RA. Relation of cue to consequence in avoiding learning. Psychonomic Science 1966; 4: 123-4.

[27] Kalat JW, Rozin P. "Learned safety" as a mechanism in long-delay taste-aversion learning in rats. Journal of Comparative Physiological Psychology 1973; 83(2): 198-207.

[28] Spector AC, Breslin P, Grill HJ. Taste reactivity as a dependent measure of the rapid formation of conditioned taste aversion: a tool for the neural analysis of taste-visceral associations. Behavioral Neuroscience 1988; 102(6): 942-52.

[29] Ballesteros MA, Gallo M. Bilateral tetrodotoxin blockade of the rat vestibular nuclei substitutes the natural unconditioned stimulus in taste aversion learning. Neuroscience Letters 2000; 279(3): 161-4.

[30] Eccles S, Kim EM, O'Hare E. Granisetron attenuates exercise-induced conditioned taste aversion in the rat. Appetite 2005; 44(3): 325-8.

[31] Guitton MJ, Dudai Y. Anxiety-like state associates with taste to produce conditioned taste aversion. Biological Psychiatry 2004; 56(11): 901-4.

[32] Masaki T, Nakajima S. Further evidence for conditioned taste aversion induced by forced swimming. Physiology and Behavior 2005; 84(1): 9-15.

[33] Revillo, DA, Spear NE, Arias C. Ontogenetic differences in sensitivity to LiCl- and amphetamine-induced taste avoidance in preweanling rats. Chemical Senses 2011; 36(6): 565-77.

[34] St. John SJ, Pour L, Boughter JD. Phenylthiocarbamide produces conditioned taste aversion in mice. Chemical Senses 2005; 30(5): 377-82.

[35] Traverso LM, Ruiz G, De la Casa LG. MK-801 induces a low intensity conditioned taste aversion. Pharmacology Biochemistry and Behavior 2012; 100(3): 645-51.

[36] Vidal J, Chamizo VD. The conditioned stimulus elicits taste aversion but not sickness behavior in conditioned mice. Neuroimmunomodulation 2010; 17(5): 325-32.

[37] Batsell WR, Best M. One bottle too many? Method of testing determines the detection of overshadowing and retention of taste aversions. Animal Learning \& Behavior 1993; 21(2): 154-8.

[38] Ossenkopp KP, Eckel LA. Toxin-induced conditioned changes in taste reactivity and the role of the chemosensitive area postrema. Neuroscience and Biobehavioral Reviews 1995; 19(1): 99-108.

[39] Yamamoto T, Shimura T, Sakai N, Ozaki N. Representation of hedonics and quality of taste stimuli in the parabrachial nucleus of the rat. Physiology and Behavior 1994; 56(6): 1197-202.

[40] Yamamoto T, Shimura T, Sako N, Yasoshima Y, Sakai N. Neural substrates for conditioned taste aversion in the rat. Behavioural Brain Research 1994; 65(2): 123-37.

[41] Bermúdez-Rattoni F, Yamamoto T. Neuroanatomy of CTA: lesions studies. In: Bures J, Bermúdez-Rattoni F, Yamamoto T. (ed.) Conditioned taste aversion: Memory of a Special Kind. New York: Oxford University Press; 1998. p28-44.

[42] Spector AC. Gustatory function in the parabrachial nuclei: implications from lesion studies in rats. Reviews in Neurosciences 1995; 6(2): 143-75. 
[43] Yamamoto T. A neural model for taste aversion learning. In: Kurihara K, Suzuki N. (ed.) Olfaction and taste, XI. Tokyo: Springer-Verlag; 1994. p471-4.

[44] Yamamoto T, Fujimoto Y, Shimura T, Sakai N. Conditioned taste aversion in rats with excitotoxic brain lesions. Neuroscience Research 1995; 22(1): 31-49.

[45] Cameron OG. Visceral brain-body information transfer. Neuroimage 2009; 47(3): 787-94.

[46] Spray KJ, Bernstein IL. Afferent and efferent connections of the parvicellular subdivision of iNTS: defining a circuit involved in taste aversion learning. Behavioural Brain Research 2004; 154(1): 85-97.

[47] Houpt TA. Molecular neurobiology of ingestive behavior. Nutrition 2000; 16(10): 827-36.

[48] Coil JD, Rogers RC, García J, Novin D. Conditioned taste aversion: vagal and circulatory mediation of the toxic unconditioned stimulus. Behavioral Biology 1978; 24(4): 509-19.

[49] García J, Hankins WG, Rusiniak KW. Behavioral regulation of the milieu interne in man and rat. Science 1974; 185(4154): 824-31.

[50] Sakai N, Yamamoto T. Possible routes of visceral information in the rat brain in formation of conditioned taste aversion. Neuroscience Research 1999; 35(1): 53-61.

[51] Barot SK, Kyono Y, Clark EW, Bernstein IL. Visualizing stimulus convergence in amygdala neurons during associative learning. Proceedings of the National Academy of Sciences of USA 2008; 105(52): 20959-63.

[52] Bahar A, Samuel A, Hazvi S, Dudai Y. The amygdalar circuit that acquires taste aversion memory differs from the circuit that extinguishes it. European Journal of Neuroscience 2003; 17(7): 1527-30.

[53] Bahar A, Dorfman N, Dudai Y. Amygdalar circuits required for either consolidation or extinction of taste aversion memory are not required for reconsolidation. European Journal of Neuroscience 2004; 19(4): 1115-8.

[54] Ma L, Wang DD, Zhang TY, Yu H, Wang Y, Huang SH, et al. Region-specific involvement of BDNF secretion and synthesis in conditioned taste aversion memory formation. The Journal of Neuroscience 2011; 31(6): 2079-90.

[55] McGaugh JL, Introini-Collison IB, Cahill L, Munsoo K, Liang KC. Involvement of the Amygdala in Neuromodulatory influences on Memory Storage. In: Aggleton JP. (ed.) The Amygdala: Neurobiological Aspects of Emotion, Memory, and Mental Dysfunction. New York: Wiley-Liss, Inc.; 1992. p431-51.

[56] Rodriguez-Ortiz CJ, Balderas I, Saucedo-Alquicira F, Cruz-Castañeda P, BermudezRattoni F. Long-term aversive taste memory requires insular and amygdala protein degradation. Neurobiology of Learning \& Memory 2011; 95(3): 311-5.

[57] Welzl H, D'Adamo P, Lipp HP. Conditioned taste aversion as a learning and memory paradigm. Behavioral Brain Research 2001; 125(1-2): 205-13.

[58] Ge H, Chiesa R, Pena de Ortiz S. Hzf-3 expression in the amygdala after establishment of conditioned aversion. Neuroscience 2003; 120(1): 1-4. 
[59] Han Z, Yan JQ, Luo GG, Liu Y, Wang YL. Leptin receptor expression in the basolateral nucleus of amygdala of conditioned taste aversion rats. World Journal of Gastroenterology 2003; 9(5): 1034-7.

[60] Yamamoto T, Shimura T, Sako N, Sakay N. c-fos immunohistochemical study on brainstem mechanisms of conditioned taste aversion in the rat. Abstracts of the Fourth IBRO Congress at Kyoto 1995; 393.

[61] Panguluri SK, Kuwabara N, Kang Y, Cooper N, Lundy RF. Conditioned taste aversion dependent regulation of amygdala gene expression. Physiology \& Behavior 2012; 105(4): 996-1006.

[62] Miranda MI, LaLumiere RT, Bue TV, Bermúdez-Rattoni F, McGaug JL. Blockade of noradrenergic receptors in the basolateral amygdala impairs taste memory. European Journal of Neuroscience 2003; 18(9): 2605-10.

[63] Reilly S, Bornovalova MA. Conditioned taste aversion and amygdala lesions in the rat: a critical review. Neuroscience \& Biobehavioral Reviews 2005; 29(7): 1067-88.

[64] Buresova O. Neocortico-amygdalar interaction in the conditioned taste aversion in rats. Activitas Nervosa Superior 1978; 20(3): 224-30.

[65] Nachman M, Ashe JH. Effects of basolateral amydala lesions on neophobia, learned taste aversions, and sodium appetite in rats. Journal of Comparative and Physiological Psychology 1974; 87(4): 622-43.

[66] Kesner RP, Berman RF, Tardif R. Place and taste aversion learning: role of basal forebrain, parietal cortex and amygdala. Brain Research Bulletin 1992; 29(3-4): 345-53.

[67] Yasoshima Y, Yamamoto T, Kobayashi K. Amygdala-dependent mechanisms underlying memory retrieval of conditioned taste aversion. Chemical Senses 2005; 30(1): 158-9.

[68] Aggleton JP, Petrides M, Iversen SD. Differential effects of amygdaloid lesions on conditioned taste aversion learning by rats. Physiology and Behavior 1981; 27(3): 397400.

[69] Kolakowska L, Larue-Achagiotis C, Le Magnen ET. Effets comparés de la lésion du noyau latéral de l'amygdale sur la néophobie et l'aversion gustative conditionnée chez la rat. Physiology and Behavior 1984; 32(4): 647-51.

[70] Rollins BL, Stines SG, McGuire HB, King BM. Effects of amygdala lesions on body weight, conditioned taste aversion, and neophobia. Physiology and Behavior 2001; 72(5): 735-42.

[71] Dunn LT, Everitt BJ. Double dissociations of the effects of the amygdala and insular cortex lesions on conditioned taste aversion, passive avoidance and neophobia in the rat using the excitotoxin ibotenic acid. Behavioral Neuroscience 1988; 102(1): 3-23.

[72] Fitgerald RE, Burton MJ. Effects of small basolateral amygdala lesions on ingestion in the rat. Physiology and Behavior 1981; 27(3): 431-7.

[73] Galaverna OG, Seeley RJ, Berridge KC, Grill HJ, Epstein AN, Schulkin J. Lesions of the central nucleus of the amygdala. I: Effects on taste reactivity, taste aversion learning and sodium appetite. Behavioral Brain Research 1993; 59(1-2): 11-7. 
[74] Schafe GE, Bernstein IL. Forebrain contribution to the induction of a brainstem correlate of conditioned taste aversion: I. The amygdala. Brain Research 1996; 741(1-2): 109-16.

[75] Bermúdez-Rattoni F, Ramírez-Lugo L, Gutiérrez R, Miranda MI. Molecular signals into the insular cortex and amygdala during aversive gustatory memory formation. Cellular and Molecular Neurobiology 2004; 24(1): 25-36.

[76] Escobar ML, Alcocer I, Chao V. The NMDA receptor antagonist CPP impairs conditioned taste aversion and insular cortex long-term potentiation in vivo. Brain Research 1998; 812(1-2): 246-51.

[77] Josselyn SA, Kida S, Silva AJ. Inducible repression of CREB function disrupts amygdale-dependent memory. Neurobiology of Learning \& Memory 2004; 82(2): 15963.

[78] Lamprecht R, Hazvi S, Dudai Y. cAMP response element-binding protein in the amygdala is required for long-but not short-term conditioned taste aversion memory. Journal of Neuroscience 1997; 17(21): 8443-50.

[79] Miranda MI, McGaugh JL. Enhancement of inhibitory avoidance and conditioned taste aversion memory with insular cortex infusions of 8-Br-cAMP: involvement of the basolateral amygdala. Learning and Memory 2004; 11(3): 312-7.

[80] Pennanen L, Welzl H, D'Adamo P, Nitsch RM, Gotz J. Accelerated extinction of conditioned taste aversion in P301L tau transgenic mice. Neurobiology of Disease 2004; 15(3): 500-9.

[81] Bermúdez-Rattoni F, McGaugh JL. Insular cortex and amygdala lesions differentially affect acquisition of inhibitory avoidance and conditioned taste aversion. Brain Research 1991; 549(1): 165-70.

[82] Pacheco-López G, Niemi MB, Kou W, Härting M, Fandrey J, Schedlowski M. Neural substrates for behaviorally conditioned immunosuppression in the rat. The Journal of Neuroscience 2005; 25(9): 2330-7.

[83] Dwyer DM. Lesions of the basolateral, but not central, amygdala impair flavour-taste learning based on fructose or quinine reinforcers. Behavioral Brain Research 2011; 220(2): 349-53.

[84] Morris R, Frey S, Kasambira T, Petrides M. Ibotenic acid lesions of the basolateral, but not the central, amygdala interfere with conditioned taste aversion: Evidence from a combined behavioral and anatomical tract-tracing investigation. Behavioral Neuroscience 1999; 113(2): 291-302.

[85] Schafe GE, Thiele TE, Bernstein IL. Conditioning method dramatically alters the role of amygdala in taste aversion learning. Learning and Memory 1998; 5(6): 481-92.

[86] Wilkins EE, Bernstein IL. Conditioning method determines patterns of c-fos expression following novel taste-illness pairing. Behavioural Brain Research 2006; 169(1): 93-7.

[87] Touzani K, Taghzouti K, Velley L. Increase of the aversive value of taste stimuli following ibotenic acid lesion of the central amygdaloid nucleus in the rat. Behavioral Brain Research 1997; 88(2): 133-42. 
[88] Kwon B, Houpt TA. Mitogen-activated protein kinase in the amygdala plays a critical role in lithium chloride-induced taste aversion learning. Neurobiology of Learning \& Memory 2012; 97(1): 132-9.

[89] Ferry B, Sandner G, Di Scala G. Neuroanatomical and functional specificity of the basolateral amygdaloid nucleus in taste-potentiate odor aversion. Neurobiology of Learning \& Memory 1995; 64(2): 169-80.

[90] Gallo M, Roldán G, Bures J. Differential involvement of gustatory insular cortex and amygdala in the acquisition and retrieval of conditioned taste aversion in rats. Behavioral Brain Research 1992; 52(1): 91-7.

[91] Yamamoto T, Fujimoto Y. Brain mechanisms of taste aversion learning in the rat. Brain Research Bulletin 1991; 27(3-4): 403-8.

[92] Yamamoto T, Azuma S, Kawamura Y. Functional relations between the cortical gustatory area and the amygdala: electrophysiological and behavioral studies in rats. Experimental Brain Research 1984; 56(1): 23-31.

[93] Bernardis LL, Bellinger LL. The lateral hypothalamic area revisited: ingestive behavior. Neuroscience \& Biobehavioral Reviews 1996; 20(2): 189-287.

[94] Lundy RF, Norgren R. Activity in the hypothalamus, amygdala, and cortex generates bilateral and convergent modulation of pontine gustatory neurons. Journal of Neurophysiology 2004; 91(3): 1143-57.

[95] Bielavska E, Roldan G. Ipsilateral connections between the gustatory cortex, amygdala and parabrachial nucleus are necessary for acquisition and retrieval of conditioned taste aversion in rats. Behavioural Brain Research 1996; 81(1-2): 25-31.

[96] Gallo M, Bures J. Acquisition of conditioned taste aversion in rats is mediated by ipsilateral interaction of cortical and mesencephalic mechanisms. Neuroscience Letters 1991; 133(2): 187-90.

[97] Schafe GE, Fitts DA, Thiele TE, LeDoux JE, Bernstein IL. The induction of c-Fos in the NTS after taste aversion learning is not correlated with measures of conditioned fear. Behavioral Neuroscience 2000; 114(1): 99-106.

[98] Tokita K, Karádi Z, Shimura T, Yamamoto T. Centrifugal inputs modulate taste aversion learning associated parabrachial neuronal activities. Journal of Neurophysiology 2004; 92(1): 265-79.

[99] Yamamoto T. Central mechanisms of roles of taste in reward and eating. Acta Physiologica Hungarica 2008; 95(2): 165-86.

[100] Hall G. Perceptual and associative learning. Oxford: Clarendon Press; 1991.

[101] Hall G, Channell S. Context specificity of latent inhibition in taste aversion learning. Quarterly Journal of Experimental Psychology 1986; 38(2): 121-39.

[102] Klamer D, Pålsson E, Wass C, Archer T, Engel JA, Svensson L. Antagonism of the nitric oxide synthase inhibitor, L-NAME, of the effects of phencyclidine on latent inhibition in taste aversion conditioning. Behavioural Brain Research 2005; 161(1): 60-8.

[103] Lubow RE. Latent inhibition. Psychological Bulletin 1973; 79(6): 398-407. 
[104] Lubow RE. Latent inhibition and conditioned theory. Cambridge: Cambridge University Press; 1989.

[105] Traverso LM, Ruiz G, De la Casa LG. Latent inhibition disruption by MK-801 in a conditioned taste-aversion paradigm. Neurobiology of Learning \& Memory 2003; 80(2): 140-6.

[106] Reilly S, Bornovalova M, Dengler C, Trifunovic R. Effects of excitotoxic lesions of the gustatory thalamus on latent inhibition and blocking of conditioned taste aversion in rats. Brain Research Bulletin 2003; 62(2): 117-28.

[107] Roman C, Lin JY, Reilly S. Conditioned taste aversion and latent inhibition following extensive taste preexposure in rats with insular cortex lesions. Brain Research 2009; 1259: 68-73.

[108] Schmajuk NA, Lam YW, Christiansen BA. Latent inhibition of the rat eyeblink response: effect of hippocampal aspiration lesions. Physiology Behavioural 1994; 55(3): 597-601.

[109] Schmajuk NA, Lam YW, Gray JA. Latent inhibition: a neural network approach. Journal of Experimental Psychology: Animal Behavior Processes 1996; 22(3): 321-49.

[110] Stevenson CW, Gratton A. Role of basolateral amygdala dopamine in modulating prepulse inhibition and latent inhibition in the rat. Psychopharmacology 2004; 176(2): 139-45.

[111] Turgeon SM, Reichstein DA. Decreased striatal c-Fos accompanies latent inhibition in a conditioned taste aversion paradigm. Brain Research 2002; 924(1): 120-3.

[112] Weiner I, Feldon J. Phencyclidine does not disrupt latent inhibition in rats: implications for animal models of schizophrenia. Pharmacology and Biochemistry of Behavior 1992; 42(4): 625-31.

[113] Weiner I, Feldon J. The switching model of latent inhibition: an update of neural substrates. Behavioural Brain Research 1997; 88(1): 11-25.

[114] Weiner I, Tarrasch R, Feldon J. Basolateral amygdala lesions do not disrupt latent inhibition (LI). Behavioral Brain Research 1995; 72(1-2): 73-81.

[115] Schmajuk NA, Cox L, Gray JA. Nucleus accumbens, entorhinal cortex and latent inhibition: a neural network model. Behavioural Brain Research 2001; 118(2): 123-41.

[116] Hatfield T, Han JS, Conley M, Gallagher M, Holland P. Neurotoxic lesions of basolateral, but not central, amygdala interfere with Pavlovian second-order conditioning and reinforcer devaluation effects. Journal of Neuroscience 1996; 16(16): 5256-65.

[117] Coutureau E, Blundell JP, Killcross S. Basolateral amygdala lesions disrupt latent inhibition in rats. Brain Research Bulletin 2001; 56(1): 49-53.

[118] Schauz C, Koch M. Blockade of NMDA receptors in the amygdala prevents latent inhibition of fear-conditioning. Learning and Memory 2000; 7(6): 393-9.

[119] Holland PC, Gallagher M. Amygdala central nucleus lesions disrupt increments, but not decrements, in conditioned stimulus processing. Behavioral Neuroscience 1993; 107(2): 246-53. 
[120] Radulovic J, Kammermeier J, Spiess J. Relationship between fos production and classical fear conditioning: effects of novelty, latent inhibition, and unconditioned stimulus preexposure. The Journal of Neuroscience 1998; 18(18): 7452-61.

[121] Buhusi CV, Gray JA, Schmajuk NA. Perplexing effects of hippocampal lesions on latent inhibition: a neural network solution. Behavioural Neuroscience 1998; 112(2): 31651.

[122] Ellenbroek BA, Knobbout DA, Cools AR. The role of mesolimbic and nigrostriatal dopamine in latent inhibition as measured with the conditioned taste aversion paradigm. Psychopharmacology 1997; 129(2): 112-20.

[123] St. Andre J, Reilly S. Effects of central and basolateral amygdala lesions on conditioned taste aversion and latent inhibition. Behavioral Neuroscience 2007; 121(1): 90-9.

[124] Bouton ME. Context, time, and memory retrieval in the interference paradigms of Pavlovian learning. Psychological Bulletin 1993; 114(1): 80-99.

[125] Bouton ME, García-Gutiérrez A. Intertrial interval as a contextual stimulus. Behavioural Processes 2006; 71(2-3): 307-17.

[126] Bouton ME, Westbrook RF, Corcoran KA, Maren S. Contextual and temporal modulations of extinction: behavioral and biological mechanisms. Biological Psychiatry 2006; 60(4): 352-60.

[127] Ward-Robinson J, Honey RC. A novel contextual dimension for use with an operant chamber: From simple to hierarchical forms of learning. Journal of Experimental Psychology: Animal Behavior Processes 2000; 26(3): 358-63.

[128] Escobar M, Arcediano F, Miller RR. Latent inhibition and contextual associations. Journal of Experimental Psychology: Animal Behavior Processes 2002; 28(2): 123-36.

[129] Quintero E, Díaz E, Vargas JP, Schmajuk N, López JC, De la Casa LG. Effects of context novelty vs. familiarity on latent inhibition with a conditioned taste aversion procedure. Behavioural Processes 2011; 86(2): 242-9.

[130] Revillo DA, Arias C, Spear NE. The unconditioned stimulus pre-exposure effect in preweanling rats in taste aversion learning: Role of the training context and injection cues. Developmental Psychobiology. In press 2012.

[131] Kwok DW, Boakes RA. Blocking of acquisition of a taste aversion by a context experienced prior to the taste. Behavioural Processes 2012; 89(1): 27-9.

[132] Rosas JM, Bouton ME. Renewal of a conditioned taste aversion upon return to the conditioning context after extinction in another one. Learning and Motivation 1997; 28(2): 216-29.

[133] Pearce JM, Bouton ME. Theories of associative learning in animals. Annual Review of Psychology 2001; 52: 111-39.

[134] Manrique T, Molero A, Ballesteros MA, Morón I, Gallo M, Fenton A. Time of daydependent latent inhibition taste aversion learning in rats. Neurobiology of Learning \& Memory 2004; 82(2): 77-80. 
[135] Morón I, Manrique T, Molero A, Ballesteros MA, Gallo M, Fenton A. The contextual modulation of conditioned taste aversions by the physical environment and time of day is similar. Learning \& Memory 2002; 9(5): 218-23.

[136] Holland PC, Bouton ME. Hippocampus and context in classical conditioning. Current Opinion in Neurobiology 1999; 9(2): 195-202.

[137] Chen CC, Shen JW, Chung NC, Min MY, Cheng SJ, Liu IY. Retrieval of contextassociated memory is dependent on the $\mathrm{Ca}(\mathrm{v}) 3.2$ T-type calcium channel. PLoS One 2012; 7(1): e29384.

[138] Corcoran KA, Maren S. Hippocampal inactivation disrupts contextual retrieval of fear memory alter extinction. Journal of Neuroscience 2001; 21(5): 1720-6.

[139] de Oliveira Alvares L, Einarsson EO, Santana F, Crestani AP, Haubrich J, Cassini LF, et al. Periodically reactivated context memory retains its precision and dependence on the hippocampus. Hippocampus 2011; 22(5): 1092-5.

[140] Cangioli I, Baldi E, Mannaioni PF, Bucherelli C, Blandina P, Passani MB. Activation of histaminergic $\mathrm{H} 3$ receptors in the rat basolateral amygdala improves expression of fear memory and enhances acetylcholine release. European Journal of Neuroscience 2002; 16(3): 521-8.

[141] Hobin JA, Goosens KA, Maren S. Context-dependent neural activity in the lateral amygdala represents fear memories after extinction. The Journal of Neuroscience 2003; 23(23): 8410-6.

[142] Lee HJ, Choi JS, Brown TH, Kim JJ. Amygdalar NMDA receptors are critical for the expression of multiple conditioned fear responses. Journal of Neuroscience 2001; 21(11): 4116-24.

[143] Hetzel A, Meredith GE, Rademacher DJ, Rosenkranz JA. Effect of amphetamine place conditioning on excitatory synaptic events in the basolateral amygdala ex vivo. Neuroscience 2012; 206: 7-16.

[144] Holland PC, Petrovich GD, Gallagher M. The effects of amygdala lesions on conditioned stimulus-potentiated eating in rats. Physiology and Behavior 2002; 76(1): 117-29.

[145] Katz DB, Rogers RF, Steinmetz JE. Novel factors contributing to the expression of latent inhibition. Behavioral Neuroscience 2002; 116(5): 824-36.

[146] Maren S, Holt W. The hippocampus and contextual memory retrieval in Pavlovian conditioning. Behavioural Brain Research 2000; 110(1-2): 97-108.

[147] Molero A, Morón I, Ballesteros MA, Manrique T, Fenton A, Gallo M. Hippocampus, temporal context and taste memories. Chemical Senses 2005; 30(1): 160-1.

[148] Stehberg J, Moraga-Amaro R, Simon F. The role of the insular cortex in taste function. Neurobiology of Learning \& Memory 2011; 96(2): 130-5.

[149] Guzmán-Ramos K, Bermúdez-Rattoni F. Post-learning molecular reactivation underlies taste memory consolidation. Frontiers in Systems Neuroscience 2011; 5(79): 19. 
[150] Roozendaal B, McGaugh JL. Memory modulation. Behavioral Neuroscience 2011; 125(6): 797-824.

[151] McGaugh JL. The amygdala modulates the consolidation of memories of emotionally arousing experiences. Annual Review of Neuroscience 2004; 27: 1-28.

[152] Chavez CM, McGaugh JL, Weinberger NM. The basolateral amygdala modulates specific sensory memory representations in the cerebral cortex. Neurobiology of Learning \& Memory 2009; 91(4): 382-92.

[153] Radwanska K, Nikolaev E, Kaczmarek L. Central noradrenergic lesion induced by DSP-4 impairs the acquisition of avoidance reactions and prevents molecular changes in the amygdala. Neurobiology of Learning \& Memory 2010; 94(3): 303-11. 